through www.MyLungRisk.org and those $>5 \%$ threshold are offered a low dose CT scan.

Results The 87 healthy lung events attracted 1943 interactions and 813 completed spirometry of which 146 (18\%) were abnormal, triggering a primary care consultation. 2911 (40\%) of 7274 eligible individuals attended the lung health check, where 1107 (38\%) were offered a CT scan: of 1064 performed, 414 (39\%) were abnormal (102 [9.6\%] lung nodules and 17 [1.6\%] lung cancer (65\% resected). 726 (44\%) of the 1658 (57\%) without previously diagnosed COPD had abnormal spirometry. Based on the first year LHLP evaluation we have extended the eligible age range to 75 years, altered patient letters, and introduced a phone contact.

Conclusions This innovative project has improved access to respiratory healthcare in a deprived area of Liverpool, identified new COPD patients, and should improve outcomes for lung cancer in this disadvantaged population.

\section{S13 MANCHESTER LUNG SCREENING, TARGETING HIGH- RISK INDIVIDUALS IN DEPRIVED AREAS OF THE COMMUNITY}

${ }^{1} \mathrm{H}$ Balata, ${ }^{2} \mathrm{P}$ Crosbie, ${ }^{1} \mathrm{M}$ Evison, ${ }^{3} \mathrm{~L}$ Yarnell, ${ }^{3} \mathrm{~A}$ Threlfall, ${ }^{1} \mathrm{P}$ Barber, ${ }^{3} \mathrm{~J}$ Tonge, ${ }^{1} \mathrm{R}$ Booton. ${ }^{1}$ University Hospital of South Manchester, Manchester, UK; ${ }^{2}$ University of Manchester, Manchester, UK; ${ }^{3}$ Macmillan Cancer Improvement Partnership, South Manchester Clinical Commissioning Group, Manchester, UK

\subsection{6/thoraxjnl-2017-210983.19}

Background Lung cancer (LC) is the commonest cause of cancer-related death in the world. Screening with low-dose computer tomography (LDCT) had been shown to reduce LC specific and all-cause mortality. Benefit is greatest in those at highest risk, such as current smokers from areas of high socio-economic deprivation, yet participation in these 'hard-toreach' populations remains a challenge. The aim of this NHS implementation project was to assess LC screening within the community in deprived areas.

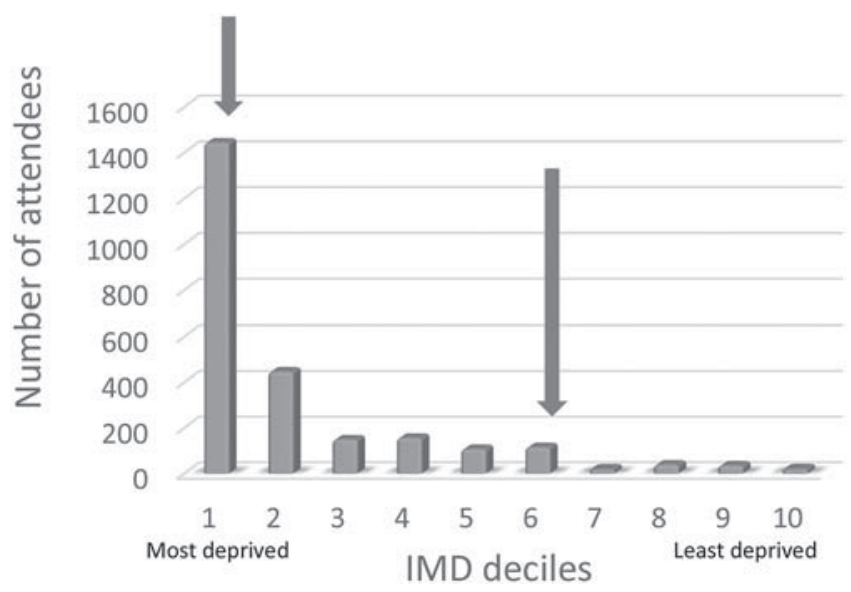

Abstract S13 Figure 1 Comparison of median Index of Multiple Deprivation (IMD) of Manchester and United Kingdom Lung Cancer Screening (UKLS) populations.

Methods Ever smokers, aged 55-74, registered at 14 participating general practitioner (GP) practices in deprived areas of Manchester were invited to attend and have a free 'Lung Health Check' (LHC) in a mobile unit located at their local shopping centres. Lung cancer risk score ( PLCO $\left._{\mathrm{M} 2012}\right)$, respiratory symptoms and spirometry were assessed as part of the LHC. Those at high risk of LC, i.e., 6 year lung cancer risk $\geq 1.51 \%$, were offered immediate LDCT in a co-located mobile CT scanner. All active smokers were provided with smoking cessation advice.

Results The maximum available capacity of the service was filled within days of going live. A total of 2541 individuals attended for a LHC and consented to data analysis. The mean age was $64.1 \pm 5.5$ and $51.0 \%(n=1,296)$ were female. $74.5 \%$ $(n=1,893)$ of participants were ranked in the lowest quintile of deprivation in England. The majority of individuals had left school by the age of $16(n=2,078 ; 81.8 \%)$, most without gaining any ' $\mathrm{O}$ ' levels $(\mathrm{n}=1,567 ; 61.7 \%)$. A significant number of participants reported a history of previous respiratory disease $(n=566 ; 22.3 \%)$, pervious cancer $(n=291 ; 11.5 \%)$, family history of LC $(n=553 ; 21.8 \%)$ or asbestos exposure $(n=612$; 24.1\%). 56.2\% $(n=1,429)$ qualified for LDCT screening of which 52.8\% were active smokers. 46 lung cancers were detected in 42 individuals, a prevalence of $3.0 \%$, of which $80.4 \%$ were early stage (I+II). A treatment with curative intent was offered to $89.1 \%$ of screen detected cancers.

Conclusion Taking lung cancer screening into the community can identify and affect those at most risk, the so-called 'hardto-reach' populations. This Results in a significant stage shift in screen detected lung cancers in deprived populations.

\section{S14 LUNG CANCER RISK PROFILES AND ELIGIBILITY OF ATTENDEES IN A LUNG CANCER SCREENING DEMONSTRATION PILOT}

${ }^{1} \mathrm{M}$ Ruparel, ${ }^{1} \mathrm{JL}$ Dickson, ${ }^{1} \mathrm{SL}$ Quaife, ${ }^{2} \mathrm{~A}$ Bhowmik, ${ }^{3} \mathrm{MN}$ Taylor, ${ }^{3} \mathrm{~A}$ Ahmed, ${ }^{3} \mathrm{PJ}$ Shaw, ${ }^{2} S$ Burke, ${ }^{2} \mathrm{MJ}$ Soo, ${ }^{4} \mathrm{~A}$ Devaraj, ${ }^{3} \mathrm{~N}$ Navani, ${ }^{5} \mathrm{SW}$ Duffy, ${ }^{6} \mathrm{DR}$ Baldwin, ${ }^{1} \mathrm{~J}$ Waller, ${ }^{1} \mathrm{SM}$ Janes. ${ }^{1}$ University College London, London, UK; ${ }^{2}$ Homerton University Hospital, London, UK; ${ }^{3}$ University College London Hospital, London, UK; ${ }^{4}$ Royal Brompton Hospital, London, UK; ${ }^{5}$ Wolfson Institute of Preventive Medicine, Barts and The London School of Medicine and Dentistry, London, UK; ${ }^{6}$ David Evans Research Centre, Nottingham University Hospitals, London, UK

\subsection{6/thoraxjnl-2017-210983.20}

Introduction Lung cancer screening by Low-Dose CT (LDCT) has been shown to reduce mortality, and the harm-benefit balance of screening is optimised by screening those at higher risk. The Lung Screen Uptake Trial is a UK based randomised controlled trial of standard versus enhanced invitation methods for LDCT screening in more deprived communities.

Methods Patients aged 60 to 75, at higher risk of lung cancer by virtue of their recorded smoking history, were invited to a 'lung health check appointment' on behalf of their GP. Attendees at one of two secondary care sites, underwent a nurse consultation that included a lung cancer risk assessment. Participants were eligible for LDCT if they met any of the following three criteria: NLST-like criteria* ( $\geq 30$ pack-year smoking history and given up $\leq 15$ years ago); PLCO $_{\mathrm{m} 2012}$ score $\geq 1.51 \%$; or LLP score $\geq 2.5 \%$. This abstract focuses on the performance of the different eligibility criteria.

Results At the time of analysis, 1997 individuals had been invited to screening and 936 attended and were enrolled into the study. 854 participants were eligible for LDCT by fulfilling any of the 3 criteria above, and 718 went on to have LDCT. The mean age of participants was 66.0 (SD 4.16), $54.4 \%$ were male and the mean smoking pack-year history was 39.7 (SD 24.9). After a median of 9.7 months follow up, 17 lung cancers were confirmed. Ten suspicious pulmonary 
nodules are undergoing diagnostic work up under the lung cancer multidisciplinary team (MDT) and 80 indeterminate nodules are under CT surveillance. The distribution of these cancers and nodules by eligibility criteria is shown in Table 1 .

Abstract S14 Table 1 Number of cancers and nodules by eligibility criteria *NLST criteria but with modified age range of 60 to 75 years

\begin{tabular}{lllll}
\hline & $\begin{array}{l}\text { PLCO }_{\text {m2012 }} \\
\text { positive }\end{array}$ & $\begin{array}{l}\text { LLP } \\
\text { positive }\end{array}$ & $\begin{array}{l}\text { NLST-like* } \\
\text { positive }\end{array}$ & $\begin{array}{l}\text { Total in } \\
\text { cohort }\end{array}$ \\
\hline Had CT & 576 & 661 & 493 & 718 \\
$\begin{array}{l}\text { Indeterminate nodules } \\
\text { Suspicious nodule referred }\end{array}$ & 64 & 74 & 58 & 80 \\
to MDT & 8 & 9 & 7 & 10 \\
\begin{tabular}{l} 
Confirmed cancers \\
\hline
\end{tabular} & 17 & 16 & 13 & 17 \\
\hline
\end{tabular}

Conclusions Using the NLST-like* criteria to determine eligibility would mean the fewest number screened, with 4 fewer cancers detected. The $\mathrm{PLCO}_{\mathrm{m} 2012}$ score was the most reliable way to detect cancers and resulted in less individuals screened than with use of the LLP score. Further follow up and review of the data is required to fully establish the most effective tool for determining eligibility into LDCT screening though the PLCO $_{\mathrm{m} 2012}$ score shows the most promise with the available data.

\section{S15 IMPROVING THE RISK STRATIFICATION FOR MALIGNANCY IN SMALL PULMONARY NODULES FROM AN UNSELECTED PATIENT POPULATION}

${ }^{1} \mathrm{~A}$ Talwar, ${ }^{2} \mathrm{JMY}$ Willaime, ${ }^{1} \mathrm{~N}$ Rahman, ${ }^{2} \mathrm{M}$ Gooding, ${ }^{3} \mathrm{~T}$ Kadir, ${ }^{1} \mathrm{~F}$ Gleeson. ${ }^{1} \mathrm{Oxford}$ University Hospitals NHS Foundation Trust, Oxford, UK; ${ }^{2}$ Mirada Medical Ltd, Oxford, UK; ${ }^{3}$ Optellum Ltd, Oxford, UK

10.1136/thoraxinl-2017-210983.21
Introduction Distinguishing between benign and malignant small pulmonary nodules (PNs) detected on CT scanning is a significant challenge. Such nodules are commonly detected in clinical practice as incidental findings or in patients with a history of prior malignancy. CT texture analysis (CTTA) has been proposed as a potential imaging biomarker in tumour characterisation. Image texture refers to the statistical analysis of spatial intensity variations of the pixels within an image to produce a CT texture score. This score is then mapped onto a probability of malignancy from $0-1$.

Aims and Objectives

- To create a registry of patients with small solid PNs from an unselected population of patients.

- Patient demographic data were combined with information acquired from CT derived parameters such as shape, size, and texture analysis (CTTA) to develop and validate a generalised linear model to determine the probability of malignancy of PNs.

- A parallel prospective interventional cohort study was also conducted to assess whether CTTA repeatability was comparable to automatic volumetric measurements when a patient is scanned twice on the same day.

Methods Between January 2012 to September 2014, 1008 patients presenting with small solid PNs were identified. The gold standard diagnosis of the nodules was established by histology or nodule stability at 2 years of CT follow-up.

Results The prevalence of malignant PNs was 31.6\% (319/ 1008). Significant independent predictors of malignancy included prior history of malignancy within 5 years $(\mathrm{OR}=117.4,(95 \%$ confidence interval(CI)):67.1 to 272.8, $\mathrm{p}<0.001)$; larger nodule diameter $(\mathrm{OR}=9.7, \mathrm{CI}: 4.1$ to 17.6 , $\mathrm{p}<0.001)$; nodule count $(\mathrm{OR}=1.6, \mathrm{CI}: 1.3$ to $1.8, \mathrm{p}<0.001)$ and nodule spiculation $(\mathrm{OR}=118.4, \mathrm{CI}: 61.9$ to 772.3 , $\mathrm{p}<0.001)$. The models' performance using the area under the ROC curve (AUC) was 0.969. When CTTA was used alone the AUC was 0.800 (figure 1). CTTA displayed ULR and LLR

Abstract S15 Figure 1 (A) Patient demographics and nodule characteristics, (B) Performance of clinical models (AUC is area under the ROC curve), and (C) Bland-altman plot to show variability in texture feature scores and volumetry for 40 Pulmonary nodules. 